\title{
Challenges For Universities Lecturers In Vietnam
}

\author{
Nguyen Huu Chau \\ Lecturer, \\ Vietnam National University
}

\begin{abstract}
Vietnamese universities are under the process of changing training model to creditbased system from academic year system. It was acknowledged that the new model would increase workload and also diversify activities of lecturers in teaching activity. This paper firstly reviews teaching activities in the credit-based training approach. To explore the existing situation of the transition to credit-based system, the author uses a mixed method of survey research and interviews with lectures and students of a University in Vietnam. The study's result shows that there were already an increase in workload and diversity in activities of lecturers. However, only a small number of teaching staff meets the demands of credit-based. Main reasons are resulted from the awareness of lecturers and students as well as the effects of the current outdated policies. This paper suggests several solutions to amend those policies that they are more practical and suitable for the teaching activities under the credit system.
\end{abstract}

Keywords: higher education ; teaching activity; credit based training system

\section{INTRODUCTION}

In recent years, Vietnamese universities have been seen to have "forwarding steps" in the application of credit-based approaching teaching to integrate with the international education system. Credit-based training model which is, very much different from the academic year system, requires fundamental changes in teaching activities to meet the demand of new training system in higher education. As noted by several researchers [1, 2], the application of credit-based system would increase workload and also diversify activities of lecturers.

This paper firstly reviews theoretical knowledge in increasing workload and diversifying activities of teaching activities that a teacher implements under credit-based training system. . If an increase in workload exists, to what extent it will be? The results of survey to investigate the existing teaching activities in a Vietnamese university after the credit based system has been introduced for nice years are also presented. A Southern university has been selected as a case for this study

\section{THEORETICAL FOUNDATION}

In the credit-based system, scope and activities of teaching are very much different from the traditional system. Based on the characteristics and requirements of credit system, it can be summarized that activities and workload which related to teaching are:

Back-propagation is an iterative, gradient search, supervised algorithm which can be viewed as multiplayer non-linear method that can re-code its input space in the hidden layers and thereby solve hard learning problems. The network is trained using ANN technique until a good agreement between predicted gain settings and actual gains is reached. Preparation of lesson plan: To make sure teaching activities meet the essences of credit-based system in class, lecturers must have an appropriate preparation of teaching plan, including the following tasks:

(1) Identify teaching content, consisting of:

- Core content (students must know) 
- Closely relevant content (students should know)

- Relatively relevant content (students may know)

(2) Define the form of teaching, including:

- Objectives and contents will be implemented in the class during theoretical hours, practical hours or seminar hours.

- Objectives and contents will be solved by students through self-studying.

- Objectives or contents will be solved through self-orientation by students to satisfy their individual learning needs.

Those activities should be planned in specific and detailed approaches, such as: questions to be raised, problems to be solved, methods to be used and documents to be read, especially as learners are usually not fully aware of the role of self-study activities.

(3) Consider appropriate ways to promote the enthusiastic and active participation of students. Thus, lecturers need to take into account issues such as the objectives, contents, subjects, time to organize and decide teaching methods when preparing their lesson plan.

Implementation of teaching activities: In credit-based system, teaching staff works as a "director" who has many activities and skills, such as coordinating, controlling, encouraging and guiding students to comprehend the knowledge, methods of brainstorming, ways of selflearning, problem identification,...etc, through various teaching approaches to help students achieve the goal of each lecture and lesson.

Assessment and evaluation of learning: Under the credit-based training system, assessment and evaluation activities occur very frequently and less formative. The boundary between assessments and teaching is blurred [3]. Therefore, to make sure those activities run effectively and efficiently, lecturers should execute the following tasks:

- For the process of planning and preparing for each lesson, lecturer has to plan assessment and evaluation at the same time for the contents to be taught as well as that from student self-learning. Teaching staff can use many methods with different forms such as individual assignment or group discussion.

- Assessment activity is practically also the self-evaluation process of lecturers to improve methods and forms of assessment.

- Assessment and evaluation processes are recorded and classified by criteria. Student progress is noted to measure improvement of learner and support the final assessment results to make sure accuracy and fairness. 
Table 1: Activities and workload relate to teaching activities

\begin{tabular}{|l|l|}
\hline No. & Activities \\
\hline 1 & Planning lesson \\
1.1 & Identifying the core content (students must know) \\
1.2 & Identifying the closely relevant content (students should know) \\
1.3 & Identifying the relatively relevant content (students may know) \\
1.4 & Identifying objectives andactivities will be settled in the class \\
1.5 & Identifying objectives and contents will be solved by students through self- \\
& studying(preparation of content, issues, questions, situations ...) \\
1.6 & Evoke problems so that learners could orient and resolve to meet individual learning \\
& needs \\
1.7 & Select, decide teaching methods which promote enthusiasm of learners \\
\hline 2. & Working as a "director" \\
2.1 & Orientation \\
2.2 & Suggestion \\
2.3 & Support \\
2.4 & Guide \\
2.5 & Systemize \\
\hline 3. & Assessment and evaluation \\
3.1 & Plan assessment activities in the teaching implementing process about methods, content \\
& and time \\
3.2 & Build criteria, rating scale and tables. They are tools to support assessment activities \\
3.3 & Teachers evaluate 'products' of students and update and notify students \\
\hline 4 & Facilitator \\
4.1 & Plan to implement mentoring activities: content, time, location, methods and subjects \\
4.2 & Implementing mentoring and facilitating activities \\
\hline
\end{tabular}

- Assessment and evaluation process must be clearly defined as designing objectives, program content and must be clearly detailed in the scheme of work, e.g. ways of assessment, ratio for each kind of assessment and notify students before the first lecture so that learners can make their own plans [4]

Mentoring activities: As a learning facilitator, a lecturer has to perform tasks to encourage, guide, facilitate and communicate with students on learning contents [3]. Therefore, teacher should plan time, contents and methods for extra non-class discussions. Through those activities, lecturer also manages the process progress of student and evaluates teaching effectiveness to make appropriate changes, if necessary.

Table 1 summarizes all contents described above. From this table, we can see that the application of credit-based system leads to a growth in the workload and diversity of lecturer's activities. Therefore, it is necessary that time allocated for those activities in the new way of teaching should be increased compared to yearly training method.

\section{Methodology}

\section{METHODOLOGY AND DATA COLLECTION}

The selected university for this case study is one of largest education institutions in the south of Vietnam. It has about 22,000 students with twenty -six majors of training. This university has started applying credit-based system since 2005. Compared with other universities in Vietnam, it is considered on the average of the countrywide implementation of the credit based system. Requirements under the credit-based teaching system and way of calculating teaching hours for lecturers of the University follow the general regulations of the Ministry of Education. As such, each lecturer must fulfill, at least, 280 class lectures (each lecture is equivalent to 50 minutes). As stipulated in the internal regulations the university's 
expenditure, if teachers have working time in class higher than "standard" amount, i.e. 280 lectures, he or she will get over -teaching income. Assessment work of mid-term and final exams are compensated exclusively. However, other teaching activities such as formative evaluation or student counseling and support, lesson plan preparation are not accounted for compensation. Those activities were not considered seriously by the university as judging lecturer's outcome.

This study uses a mixed approach, combining qualitative research method (interviews) and quantitative research method (questionnaire). Information of workload and activities of the lecturer based on the credit system as well as other relevant tasks at the university are obtained through the questionnaire. Lecturers are also interviewed to attain more thoughts on their daily assignments. Activities of lecturers are also evaluated from students through questionnaire surveys and interviews.

\section{Data Collection}

The questionnaire survey was implemented in 2014 with students and staff, relatively equally distributed within the departments of the University. 100 samples for students and 100 samples for lecturers were sent out. The respondent rate was high $80 \%$ from the lectures and $73 \%$ from students. Six students and six lecturers were interviewed. Lecturers were asked to describe their daily activities that are relevant to their teaching job at the University. Students were interviewed to describe and demonstrate activities of lecturers. These interviews helped to clarify the information that had been asked in the survey.

\section{Teaching Activities}

\section{DATE ANALYSIS, FINDINGS AND DISCUSSIONS}

Based on the survey results obtained from data for teaching staff, the percentage of lecturers made proper preparation for teaching activities that met the requirements of credit-based training is shown in Table 2.

From this table, it can be seen that the number of lecturers have frequently determined the specific content which students must know (core) in preparation activities can be considered as the most positive and common activities with a very high rate of nearly $93 \%$. The determination and planning for other activities and contents decrease: identifying specific content which students should know (closely related) - 70.6\%; identifying the content which students can digest in class - 66.2\%; identifying the content, issues, questions for students 'selfstudy is just over60\%. Meanwhile, for those activities considered not to be closely relevant, less than half of the lectures regularly carry out. For instance, "identifying the content, issues, questions... which need to be addressed by students through group activities" is less than 50\% and "identifying content which students can learn" is less than $40 \%$.Similar figures were also obtained when analyzing data from student questionnaire. 
Table 2: Preparation of lesson plan

\begin{tabular}{|l|c|c|c|c|}
\hline \multicolumn{1}{|c|}{ Scale (\%) } & Never & Rarely & Occasionally & Frequently \\
\hline $\begin{array}{l}\text { Identifying specific } \\
\text { content which students } \\
\text { must know }\end{array}$ & $0 \%$ & $2.9 \%$ & $4.4 \%$ & $92.7 \%$ \\
\hline $\begin{array}{l}\text { Identifying specific } \\
\text { content which students } \\
\text { should know }\end{array}$ & $0 \%$ & $0 \%$ & $29.4 \%$ & $70.6 \%$ \\
\hline $\begin{array}{l}\text { Identifying content which } \\
\text { students can learn }\end{array}$ & $3 \%$ & $1.5 \%$ & $56.1 \%$ & $39.4 \%$ \\
\hline $\begin{array}{l}\text { Identifying the content } \\
\text { which students can digest } \\
\text { in class }\end{array}$ & $0 \%$ & $2.9 \%$ & $30.9 \%$ & $66.2 \%$ \\
\hline $\begin{array}{l}\text { Identifying the content, } \\
\text { issues, questions...for } \\
\text { student self-study }\end{array}$ & $0 \%$ & $2.9 \%$ & $36.8 \%$ & $60.3 \%$ \\
\hline $\begin{array}{l}\text { Identifying the content, } \\
\text { issues, questions... which } \\
\text { need to be addressed by } \\
\text { students through group } \\
\text { activities }\end{array}$ & $1.6 \%$ & $4.5 \%$ & $45.5 \%$ & $48.4 \%$ \\
\hline
\end{tabular}

As surveying teaching activities, we also received information from the description of lecturers as well as opinion of the learners on their lecturers' performance in class. Most lecturers have had approaches to raise the sense of enthusiasm and activeness of learners through activities such as eliciting and guiding individual and group work by questioning, problem solving and discussions. However, through the assessment of the learners as well as lecturers, it was also seen that teaching and learning quality is lower than their expectation and desire. Explanations are different between students and lecturers. Students stated that, from their side, they did not really work hard in learning activities and they only learned as being forced to do so. They also supposed that they were not aware of the value of the knowledge and skills needed for their

future career. On the other hand, lecturers blamed that the class size is too large (52\%); awareness of students was not good (48\%); teaching facilities did not meet the teaching requirements $(27 \%)$ and time in class was limited $(23 \%)$.

In short, from the result, it can be seen that the number of lecturers who meet the quantity and activities required by credit-based training system is on the medium level. Teaching activities from the lecturers has been changing in a positive way; however, factors such as the number of student in one class, supporting facilities and the awareness in learning of students hinder the quality assurance of teaching and learning under the credit system in this University.

\section{Assessment and Evaluation}

Figure 1 shows number of assessments of student in one semester. This number is not included the mid-term and final exams. 


\section{Figure 1: Number of assessments of student in a semester}

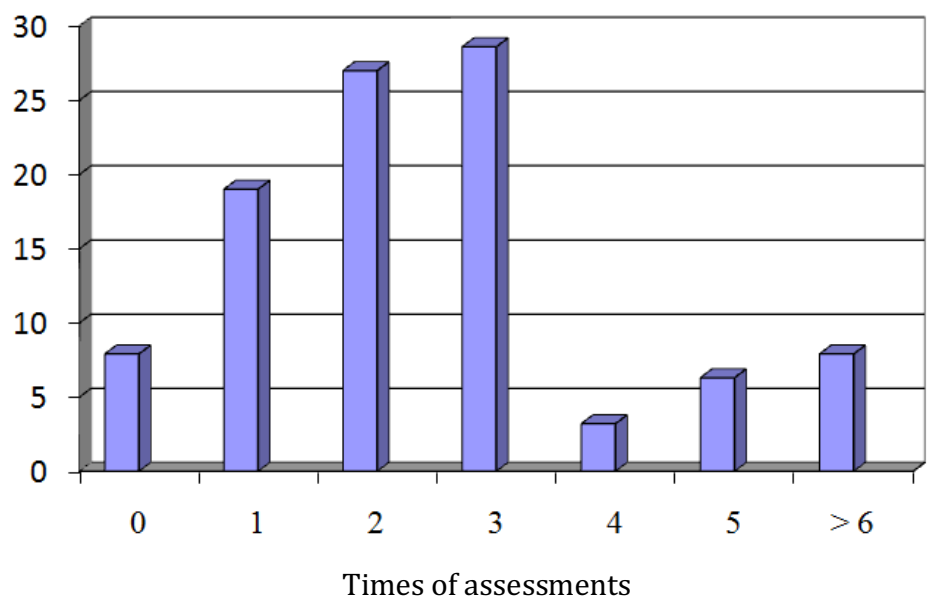

From this result, it can be seen that most of lecturers have made formative evaluation during teaching process. Number of assessments mainly varies from 1 to 3 times per semester. This activity does not include compulsory mid-term and final exams. The survey outcomes also show that there is about two third of the lecturers has prepared contents, questions, issues to examine and evaluate the learning process of students. However, only approximately one third of lecturers record the progress of students in a appropriate and logical way, such as using by tables and score management software. Based on the feedback of students, those percentages are $35 \%$ and $20 \%$, respectively. The differences between two subjects of survey can be explained as follows:

- Awareness and understanding of formative evaluation were different between these two groups. Lecturers considered this activity includes questions and answers, group presentations and individual assessment. Whereas, many students thought that formative evaluation are only activities that involve all members of the class.

- Supporting tools used to record the outcomes of assessment are not always clearly informed to students such as the criteria, method of evaluation.

Although the data has no consistency between learners and teachers, the information obtained through interviewing and surveying those groups indicated that the formative evaluation is not a common activity in teaching, at the presence. Through the survey with lecturers, it is reported that the large class size (51\%) and insufficient time for plan and implementation (31\%) are the dominant reasons leading to that situation. Some young lecturers who regularly conduct this job also admitted that they cannot guarantee that they would continue properly this time-consuming activity in the future as they get married. One of lecture described her formative evaluation job: "I taught two courses (2 credits per course) for 4 classes of approximately 50 students each. On average, each student submits two individual exercises and one exercise in group. Thus, I had to mark more than 400 essays. That number is not included 200 assignments of students as they carry out mid-term and final exams". Besides that, lecturers also need more time to input and notify results while those activities are not counted in teaching hours. Therefore, some other lecturers who come into the interview said that they did carry out formative evaluation frequently, however, the marking is only made randomly with only a few essays were selected because they did not have enough the time to do the job properly.

\section{Facilitating Activities}

Facilitating and mentoring activities must be well-planned. Those activities require lecturers to have concrete preparation such as defining meeting objectives, time, method of implementation and number of student for each session. According to survey result, only a third of lecturers involving in the survey said that they usually carry out that kind of activity. 
However, students stated that figure is only approximately $15 \%$. The difference between those two figures can be explained that lecturer usually understand that those activities include all formal and informal support, via emails or telephone while students may not agree so.

Through both questionnaire and interview, it was revealed that $80 \%$ learners want counseling and supporting activities to be formalized through pre-arranged schedule rather than "case by case" condition. More specifically, 52\% of students in the survey thought that teachers did not have plan to meet them for supporting activities.50\% of students stated that they felt afraid to ask for an appointment with their teachers and 20\% stated that the unfriendly attitude of lecturers prevented them from doing so. These are seen as main reasons hindering the counseling and supporting activities. As the result, only students who are confident and courageous usually ask their teachers for their support.

From the teacher's answers, 80\% acknowledged that they only informed the learners that "if you need any counseling and supporting activity, please contact me through emails or telephone". They stated that learners did not has demand of exchanging or supporting (44\%), large number of students (43\%) and time for those activities was not compensated by universities (35\%) are the reasons that prevent them to formalize that activity. With $15 \%$ of lecturers who did plan for exchanging and supporting activities, they acknowledged that they spent one or two meetings with students for every subject. They also emphasized that most of those activities were aimed to support the group, not for individuals.

In short, counseling and supporting activities for students are not common in the University. Only a small number of lecturers carry out this job, nevertheless, it occurs not very frequently, not really effectively. It resulted from the fact that lecturers do not have official plan and students do not have active attitude in communicating with their teachers.

\section{Suggestions}

\section{SUGGESTIONS AND CONCLUSIONS}

Based on the theoretical knowledge and the existing situation of teaching activities at the University, it shows that there is an increase in workload and diversify in teaching activities of lecturers. However, the number of lecturers who really follow requirements of the new model of training is not the majority. More importantly, those teacher admitted that they cannot continue those activities if there is no change in policy to suit the existing situation. Some proposals are thus made as the followings:

- First, working time for lecturer does not include the time in the class but also it needs to take into consideration of the preparation and counseling time. Thus, lecturer should be compensated for more time for other activities that suits the demands of the creditbased system.

- Second, university and departments should have policy and monitor system to encourage teachers to apply appropriately teaching activities based on the standards of credit system.

- Third, numbers of students in class should be decreased and good facilities should be supported for teaching activities.

- Forth, university should organize seminars and events for students to discuss methods and culture of study under the credit-based training system.

- Fifth, short training courses and seminars need to be organized for teachers to let them be familiar and competent with teaching activities under the credit system.

- Sixth, counseling and supporting jobs can be shared by young lecturers, even postgraduate students to lessen workload for lecturers and give them more time to concentrate on teaching activities. 


\section{Conclusions}

This study has investigated teaching situation of University after nearly 10 years implemented credit-based system for teaching and learning. The study findings show that, there has been an increase in the workload and a diversity in teaching activities as the credit system has been put into practice. However, the existing situation does not meet the expectation of students and lecturers as well as credit-based training standards. This gap resulted from the facts that students and lecturers are not fully aware of requirements of credit-based teaching system. Moreover, large number of students in class, shortage of time allocated for teaching and supporting activities, unsuitable and outdated regulations and policies are others main causes. In order to create motivation and satisfaction for lecturers in fulfill increasing workload and diversifying teaching activities, there should be amendments in policies and regulations to make sure they are more practical and suitable under the credit system

\section{References}

Jean, B. and Watson, D. (1994). "Managing the University Curriculum: Making Common Cause”. SRHE and open University Press Publisher

Zjhra, M. (2008). Transfusing the credit system needed to change the training program and the role of teachers. Reference document: Educational research - No.6/ 2008

Harden R. M. and Crosby J. R. (2000). The good teacher is more than a lecture -the twelve roles of the teacher. Medical teacher 22 (4): pp. 334-347

Tran DucHieu(2012). Innovating the inspecting and evaluating in university- indispensable requirements in training as the credit system. Journal of Education, No.288/2012 